
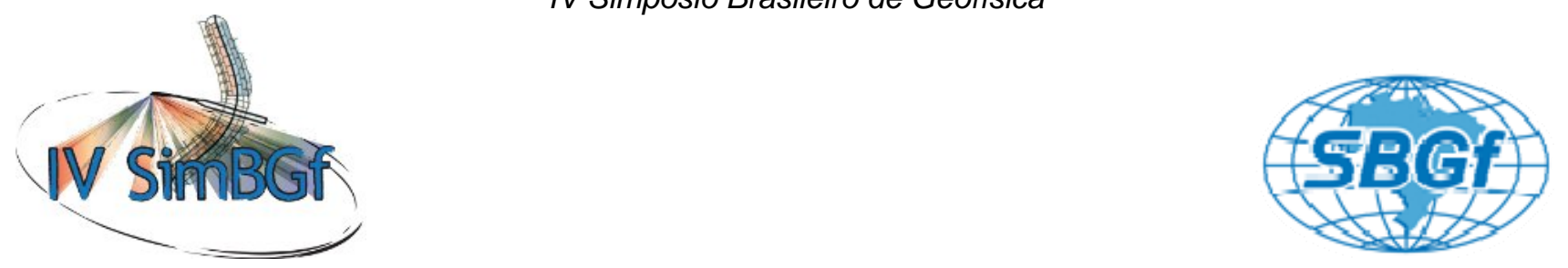

\title{
O tratamento de imagens geofísicas-geológicas em ambiente SIG gerando mapas de favorabilidade mineral para a prospecção e exploração de depósitos de ferro na região de Morro do Pilar, M.G.
}

Vassily Khoury Rolim, Terrativa Minerais S.A. (vassily.rolim@gmail.com)

Adalene Moreira Silva, Universidade de Brasília (adalene@unb.br)

Copyright 2008, SBGf - Sociedade Brasileira de Geofísica

Este texto foi preparado para a apresentação no IV Simpósio Brasileiro de Geofísica, Belém, 14 a 17 de novembro de 2010. Seu conteúdo foi revisado pelo Comitê Técnico do IV SimBGf, mas não necessariamente representa a opinião da SBGf ou de seus associados. É proibida a reprodução total ou parcial deste material para propósitos comerciais sem prévia autorização da SBGf.

\section{Resumo}

Este trabalho demonstra o uso de ferramentas geomatemáticas em ambiente de Sistemas de Informações Geográficas (SIG) combinando informações geológicas e geofísicas (gradiometria gravimétrica, gamaespectometria e magnetometria) para gerar mapas de favorabilidade mineral para a prospecção e exploração de depósitos de ferro na região de Morro do Pilar, M.G. As ferramentas usadas foram o Peso-deEvidências, a Lógica Fuzzy e Modelos de Redes Neurais. Os mapas gerados puderam evidenciar os contrastes geofísicos, separando fontes magnéticas litologicamente diferentes, realçando corpos ricos em Fe não aflorantes e destacando novos alvos ainda não conhecidos.

\section{Introdução}

O presente projeto aborda a caracterização da assinatura geológico-geofísica de corpos de formação ferrífera bandada na região de Morro do Pilar, (MG), visando à geração de modelos prospectivos para seleção de alvos de minério de ferro através da fusão e análise espacial de dados digitais, utilizando dados gravimétricos gradiométricos e magnéticos de alta resolução espacial (Projeto Morro do Pilar - BHP Billiton Metais S.A.) e gamaspectrométricos do Projeto Morro do Pilar - Serro Guanhães, Área 3 (CODEMIG - www.codemig.com.br).

\section{Geologia Local}

A geologia da Região de Morro do Pilar compreende um conjunto de metassedimentos depositados em uma bacia intra-continental que evoluiu para uma margem passiva. Os sedimentos são compostos por clásticos grosseiros (areias), clásticos finos (argilas) e sedimentos químicos onde se incluem as economicamente importantes formações ferríferas bandadas.

O Grupo Serra da Serpentina é a unidade economicamente importante da região, pois contem grandes espessuras de formações ferríferas bandadas, muito pesquisadas para minérios de ferro. Este Grupo foi dividido em uma Unidade Basal, uma Unidade Intermediária e uma Unidade de Topo. A Unidade Basal é metassedimentar com predominância de sedimentos clásticos finos, argilosos ou arenosos, composta predominantemente por filitos e mica xistos e subordinadamente quartzitos (Rolim, 2009).

A Unidade intermediária do Grupo Serra da Serpentina é composta por uma formação ferrífera bandada, do tipo Lago Superior, de cor cinza clara a cinza escura, localmente negra azulada, bandada pela alternância de bandas quartzosas e bandas ricas em especularita, hematita e, localmente, magnetita. Corpos ricos em especularita (teores de Fe acima de 60\%), cisalhados e muito foliados, bem como corpos ricos em magnetita, com comprimento de algumas centenas de metros e espessura de até $150 \mathrm{~m}$ ocorrem de forma descontínua no interior destas formações ferríferas (Rolim, 2009).

A Unidade de Topo do Grupo Serra da Serpentina é um conjunto de quartzitos brancos a amarelados, monótonos, de grão fino a médio, laminado paralelamente por níveis sub-milimétricos sericíticos.

As rochas mais antigas de provável idade arqueana a paleo-proterozoica, e que constituíam o continente antes da abertura de bacia para a deposição do Grupo Serra da Serpentina, formam um conjunto de granitos/gnaisses/migmatitos composição granítica e granodiorítica incluídos no Complexo Basal.

Cortando todas as rochas descritas ocorre uma rocha metabásica intrusiva, na forma de sills e diques com centímetros a dezenas de metros de espessura. Esta rocha encontra-se retrometamorfisada para um carbonato-talco-epidoto-clorita-xisto, está muito dobrada e foliada e penetra todas as litologias, se concentrando preferencialmente nos contatos (Rolim, 2009).

A tectônica local é compressiva, com formação de falhamentos de empurrão de direção geral norte sul, mergulho para leste e com transporte de massas de leste para oeste. A organização espacial das camadas é simples. Elas formam um monoclinal de direção geral NS e mergulho em torno de 15 a $20^{\circ}$ para $E$.

\section{Metodologia/ Problema Investigado}

A aquisição de dados gravimétricos e magnéticos foi realizada pela BHP Bilitom com o sistema AGG Falcon ${ }^{\mathrm{TM}}$ (Falcon ${ }^{\mathrm{TM}}$ Airborne Gravity Gradiometer system). O sistema Falcon é uma tecnologia de plataforma móvel com acelerômetros múltiplos que medem o tensor total do gradiente da gravidade. Consiste de quatro pacotes instrumentais principais: gradiometro gravimétrico digital, um magnetômetro, um laser scanner para registro 
topográfico e GPS diferencial. Os vôos foram realizados em linhas paralelas de direção EW, espaçadas de $250 \mathrm{~m}$, a uma altura média de $100 \mathrm{~m}$. Os dados gamaespectométricos do Projeto Morro do Pilar - Serro Guanhães, Área 3 foram adquiridos pela CODEMIG a uma altura constante $(100 \mathrm{~m})$ segundo linhas de vôo N30W, espaçadas de 250 metros.

As mapas geológicos foram produzidos por trabalhos de campo em escala de 1:5.000 usando-se como base mapa topográfico aerorestituido e imagens de satélite WordView coloridas de alta resolução.

De posse de um banco de dados geofísicos e geológico, a procura de áreas potenciais para depósitos de ferro sem ocorrências conhecidas na região estudada, foi efetuada por uma abordagem guiada pelo conhecimento (knowledge-driven). Neste tipo de análise foi fundamental a definição do modelo metalogenético descritivo para depósitos de ferro, o qual foi adaptado aos dados disponíveis. Norteados por esse modelo, os dados foram ponderados e combinados através da lógica fuzzy, redes neurais artificiais e pesos de evidência. A definição de áreas potenciais para depósitos de ferro previamente conhecidos na região foi realizada com o auxilio da técnica de pesos de evidência e de redes neurais artificiais, em uma abordagem guiada pelos dados (datadriven).

Assim, este estudo compreendeu, primeiramente, a aplicação de técnica originalmente desenvolvida para classificação de dados de sensoriamento remoto hiperespectral (Spectral Angle Mapper- SAM), aqui adaptada para uso com dados aerogeofísicos. Foi produzida uma imagem classificada SAM, onde buscouse mapear pixels similares a pontos de controle: dois pontos ricos em hematita (662.297E/7881984N e $673583 \mathrm{E} / 7872247 \mathrm{~N})$; um ponto rico em magnetita $(668344 / 7884788)$ e um ponto onde aflora canga (666518E/7881507N). Os pixels foram mapeados a partir dos produtos derivados da gravimetria gradiométrica, da magnetometria e dos dados gamaspectrométricos. Posteriormente, para analisar as classificações em termos de propriedades físicas, efetuou-se uma composição ternária RGB.

A idéia principal era mapear corpos de formação ferrífera bandada que possuam as mesmas características do ponto amostrado tanto em superfície quanto em subsuperfície. Em superfície, porque este corpo aflora e estas características estão sendo mapeadas pela baixa variação dos radiolementos $\mathrm{K}$, Th e $\mathrm{U}$ e pelo alto gradiente na amplitude do sinal analítico. A imagem SAM foi posteriormente reclassificada, com atribuição de pesos para as classes, o que permitiu selecionar as duas classes com maior pertinência para prospecção de minério de ferro.

A segunda técnica aplicada foi a modelagem por pesos de evidência (WofE), a qual foi desenvolvida a partir da combinação dos mapas evidenciais, gerados a partir dos produtos aerogeofísicos (gravimetria gradiométrica, magnetometria e gamaespectrometria), além dos pontos de treinamento relacionados a registro de ferro extraídos da base de dados disponíveis para este trabalho. Entre os vários experimentos realizados, somente dois modelos atenderam aos requisitos dos testes de condição de independência dos dados. O primeiro modelo compreende as seguintes variáveis: i) áreas com altos valores magnéticos, ii) baixos teores de potássio, tório e urânio; iii) áreas com altos valores gradiométrico. A idéia era mapear corpos magnéticos e densos e, portanto, corpos ricos em magnetita. $O$ segundo modelo compreende áreas com baixos valores magnéticos, baixos teores de potássio, tório e urânio e áreas com altos valores de gradiente gravimétrico. Ou seja, objetivase mapear corpos de hematita.

A terceira técnica empregada foi a modelagem por lógica fuzzy. Nesta modelagem foram utilizados os mesmos dados utilizados no método por pesos de evidência. Os mapas de favorabilidade foram gerados com o operador Fuzzy-Gamma, considerando diferentes combinações para os dados de entrada, bem como diferentes valores para o fator gamma.

Finalmente foi feita uma Modelagem por Redes Neurais Artificiais (RNAs) por meio da combinação dos mapas evidenciais gerados pelo métodos anteriores que apresentaram os melhores resultados: i) Modelo 1: Geologia, lineamentos magnéticos, $\mathrm{K}, \mathrm{Th}, \mathrm{U}$ e ASA e, ii) Modelo 2: Geologia fuzzificada, lineamentos magnéticos, $\mathrm{K}$, Th, $\mathrm{U}$ e ASA. Foram utilizados três sistemas de classificação por RNAs: Fuzzy Clustering, RBFLN e PNN. Os sistemas RBFLN e PNN envolvem métodos supervisionados e, portanto, necessitam de pontos de treinamento para a associação de classes. Os pontos de treinamento associados a depósitos foram os mesmos utilizados na técnica WofE. Os pontos de não-depósitos, essenciais para a classificação pelo método RBFLN, foram extraídos de áreas com baixa possibilidade de hospedar formações ferríferas bandadas, a partir do mapa de favorabilidade gerado pelo método WofE, com o auxílio adicional dos produtos derivados dos dados aerogeofísicos.

Os resultados de favorabilidade mineral para corpos ricos hematíticos e/ou magnéticos foram checados em campo por meio de mapeamentos geológicos e por furos de sondagem diamantada.

\section{Resultados}

Foram gerados diversos mapas de favorabilidade de ocorrências de corpos hematíticos e/ou magnetíticos pelos diversos métodos empregados (Figura 1). Vários alvos prospectivos foram definidos. Muitos destes alvos já eram conhecidos pelos mapeamentos geológicos realizados, mas diversos outros, até então desconhecidos, foram indicados pelos métodos. Os métodos não apresentaram a mesma sensibilidade para localização dos alvos e afloramentos já conhecidos, porém o estudo combinado de todas as imagens produzidas mostrou que a metodologia indicada permite localizar formações ferríferas bandadas contendo corpos não aflorantes ricos em hematitas e corpos ricos em magnetita, cujas anomalias magnéticas, a princípio, eram interpretadas como oriundas de corpos de rochas básicas 
intrusivas. Os alvos destacados na Figura 2 foram sondados e corpos ricos em hematita/especularita foram encontrados nos alvos NQF_009, NQF_007, NQF_006 e ricos em magnetita no alvo NQF_009A.

\section{Discussão e Conclusões}

Os modelos gerados apresentaram resultados coerentes na localização de áreas com alto potencial para ferro quando comparadas com afloramentos, dados de sondagem e ocorrências conhecidas.

Os resultados mostraram que o modelo de prospecção e exploração geológicos para a área de Morro do Pilar foi aprimorado pelo uso de métodos geofísicos e pelo uso de ferramentas geomatemáticas em plataforma GIS. Os mapas prospectivos gerados tiveram sucesso no descobrimento de novos alvos e, principalmente, na localização de corpos ricos em $\mathrm{Fe}$ em profundidade dentro de alvos já conhecidos, mas cujos afloramentos não demonstravam corretamente todo 0 potencial exploratório existente em sub-superfície.

A comparação entre os mapas prospectivos gerados pelo uso dos métodos de Peso-de-Evidência, Lógica Fuzzy e Modelos de Rede Neural tiveram boa correlação e similaridade. Porém, ocorreram algumas diferenças, sugerindo uma perda de correlação em alguns alvos. Concluímos que a Lógica Fuzzy e as Redes Neurais deram melhores resultados que os modelos de Peso-de Evidência nas áreas ao norte de Morro do Pilar, porém os Modelos de Peso-de-Evidências foram melhores nas áreas ao sul. As causas destes resulltados ainda precisão ser investigadas.

\section{Agradecimentos}

Agradecemos a Terrativa Minerais S.A, . a oportunidade de utilizar, neste artigo, os dados de seu projeto de exploração mineral em Morro do Pilar.

\section{Referências}

Diorio, P., 2009. FALCON® Airborne Gravity Gradiometer Survey - Morro do Pillar Subset - Northern QF Survey, Minas Gerais, Brazil. Data and Interpretation Report. BHP Internal Report. Inédito. 23 p.

Rolim, V.K., 2009. Geologia da região de Morro do Pilar. Relatório interno para a Terrativa Minerais S.A, Inédito. $56 \mathrm{p}$.

Zacchi, E. N. P.; Silva, A. M.; Rolim, V. K., 2008. Análise integrada de dados multi-fontes e sua aplicação no mapeamento geológico das formações ferríferas da Serra de Itapanhoacanga, MG. In: 44 Congresso Brasileiro de Geologia, 2008, Curitiba. v.1: 830-830.

Zacchi, E. N. P.; Silva, A. M.; Rolim, V. K.; Dias, G. S., 2010. Caracterização Geofísica de Formações Ferríferas Bandadas na Borda Leste da Serra do Espinhaço (MG) para a Geração de Modelos 'Knowledge Driven' para a Prospecção de Minério de Ferro. IV Simpósio Brasileiro de Exploração Mineral, Ouro Preto.

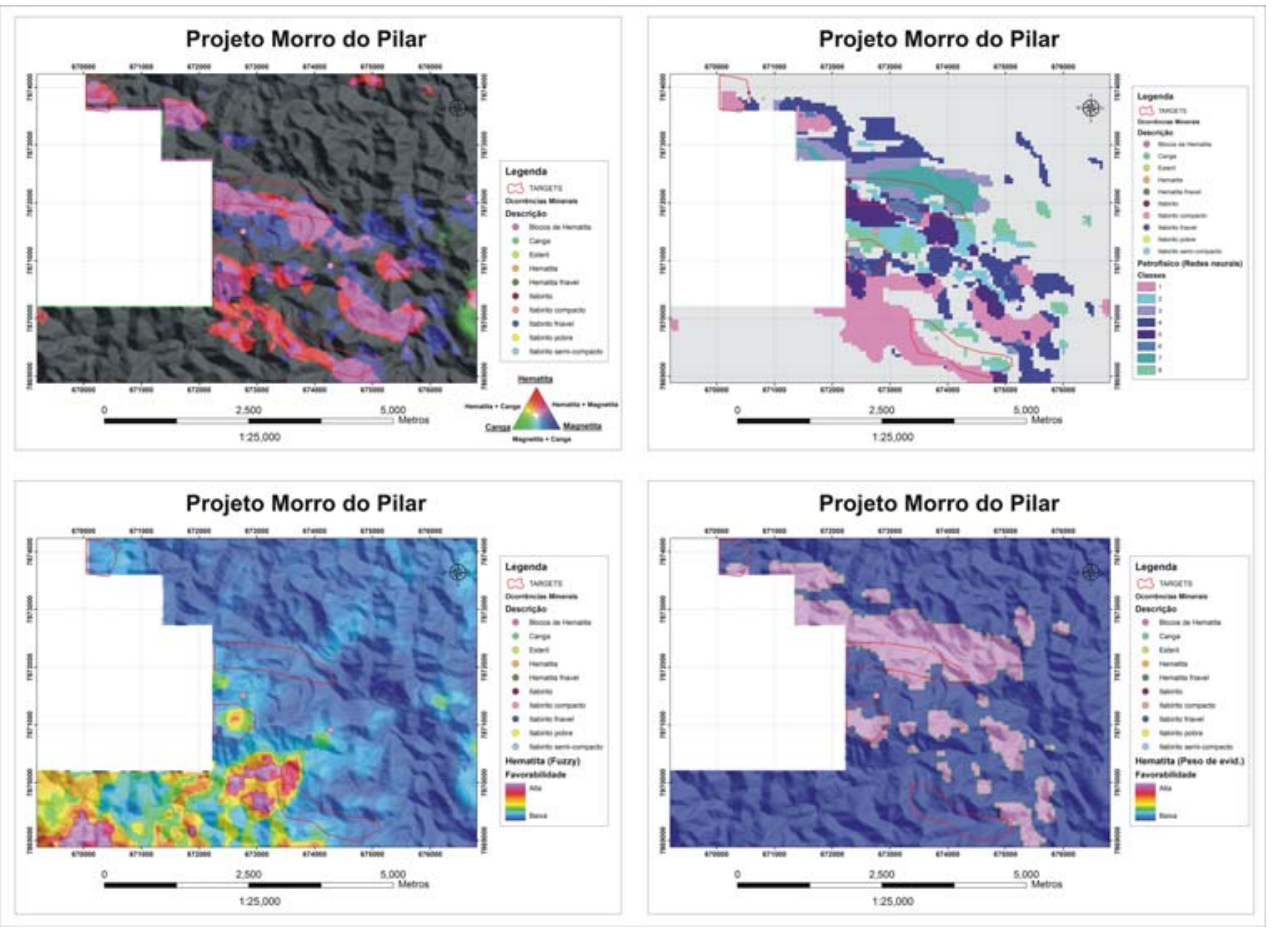

Figura 1 - Comparação dos modelos gerados para a região de Morro do Pilar na região sul de Morro de Pilar. a) Modelo gerado pela técnica de classificação SAM; b) Detalhe do modelo gerado por redes neurais; c) detalhe do modelo gerado por lógica fuzzy e d) detalhe do modelo gerado por pesos de evidência. O modelo 2.D mapeia bem novos alvos para este domínio. De forma geral os outros modelos discriminam os mesmos alvos. Porém, o modelo utilizando lógica fuzzy representa o pior cenário para este domínio. 


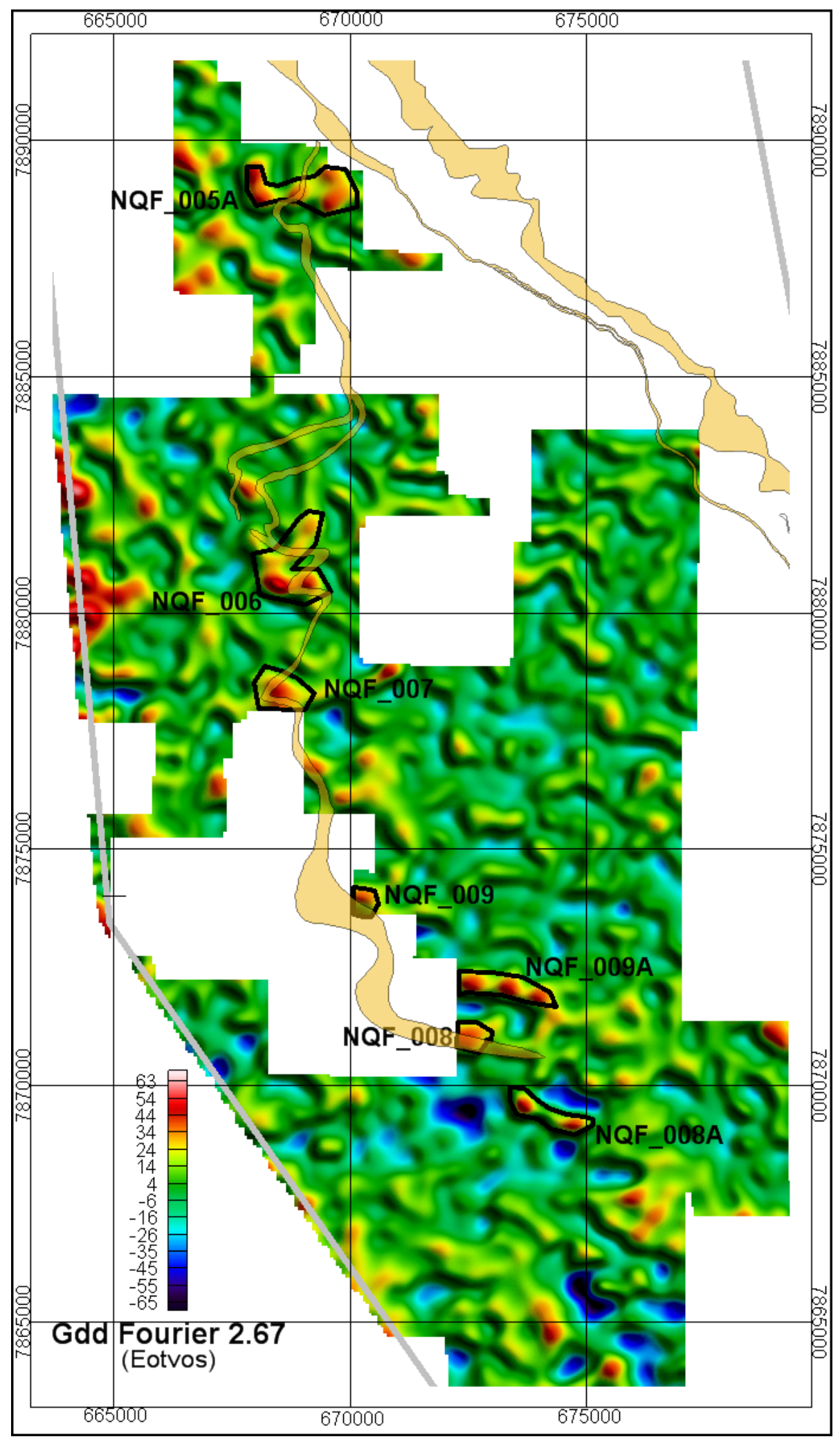

Figura 2 - Gradiente gravimétrico (Gdd Fourier) para a região de Morro do Pilar com correção de terreno de $2.67 \mathrm{~g} / \mathrm{cc}$. Em laranja observar a camada de BIF e sua correlação com anomalias e alvos mapeados (polígonos em preto) (Diorio, 2009). Os alvos NQF_009, NQF_007, NQF_006 foram furados por sondagem diamantada e revelaram corpos hematíticos ricos, não aflorantes em sub-superfície. O alvo NQF_009A se mostrou um corpo magnetítico rico também não aflorante. 